RESEARCH ARTICLE

\title{
Microhabitat Dependant the Proliferation of Microfungi in Dandak Cave of Kanger Valley National Park, India
}

\author{
Deepa Biswas ${ }^{1,2}$, Jayant Biswas ${ }^{1 *}$ \\ 'Central Laboratory, National Cave Research and Protection \\ Organization, Raipur, Chhattisgarh, India \\ ${ }^{2}$ Department of Botany, Kalinga University, Atal Nagar, New \\ Raipur, 492101, Chhattisgarh, India \\ Study Area: Dandak Cave, Bastar, Chhattisgarh, \\ India \\ Coordinates: $18^{\circ} 51^{\prime} 30^{\prime \prime} \mathrm{N} ; 8^{\circ} 57^{\prime} \mathrm{oo} " \mathrm{E}$
}

Key words: Bartaliana robillardoides, Histoplama capsulatum, Cave ecosystem, Seasonal distribution.

\section{Abstract}

The possibilities of obtaining biotechnologically potent microbes are always much from the uncommon ecological niches. In the present study, the diversity of microfungi associated with soil sediments of two distinct ecosystems existing inside a cave of Central India "Dandak" were compared. Soil samples were collected from three different seasons; Summer, Rainy, and Winter. Results revealed the Aspergillaceae and Trichomaceae family to be the most dominant over other families. Ecological contributions were also recorded in which Aspergillus niger was found in highest percent frequency $(66.67 \%)$ with $9.57 \%$ total percent contribution. Bartaliana robillardoides and Histoplama capsulatum are some of the specific types of microfungi were isolated from the soil sediments of the outer chamber of the cave. The possible reason for identifying uncommon microfungi from outer chamber of the Dandak cave has been further discussed.

located in Kanger Valley National Park, Jagadalpur. The cave is about $360 \mathrm{~m}$ in length (Biswas \& Shrotriya, 2011) and horizontally divided into two main chambers or compartments. The outer chamber is exposed directly to the epigean environmental conditions whereas the inner chamber is connected only with the outer chamber through a narrow convoluted passage. In this study, we referred both the chambers as an outer and an inner chamber. This cave suffers less anthropogenic pressure because the general entry of tourist is restricted for this cave.

Sample collection: Soil samples were collected from both the chambers (outer and inner) in three successive season Summer, Rainy and Winter during the year 2014 to 2015. Samples were taken out with the help of sterile forceps and packed it into sterile plastic bottles. One gram of soil sample was used to isolate the fungal species. For inoculation, selective media, PDA (Potato Dextrose Agar) was used and then after developed inoculated cultures were processed for further studies. Fungal isolation was done by serial dilution method. For observation and identification, standard staining method was done. The lactophenol cotton blue stain was used for fungal staining. Identifications were mainly based on morphological characteristics of the colony and microscopic examinations. It was done mainly on the basis of visual fungal culture characteristics on plates such as topography

*Corresponding Author: jb@caves.res.in 


\section{RESEARCH ARTICLE}

of the colony, mycelial growth, outline of colony, texture of colony, pigmentation of the colony, exudance of substance by the colony, colour of colony both for back and front side of Petri-plate, changes in colour of the colony and medium, diameter of the colony etc. (Gilman, 1957; Barnett \& Hunter, 1998). We also took the Professional help for proper identifications of those isolates which we failed to identify in our laboratory.

Dynamical characteristics: Fungi play an important role in the cave environment. Percentage frequency and percentage contribution of the fungal flora were also calculated for further interpretations.

\section{Results:}

A total of 38 species belonging to 14 genera and one Mycelia sterilia were isolated from soil sediment collected from both the chambers of Dandak cave during three successive seasons (Summer, Rain, and Winter). From all the collected samples 43 isolates from the outer chamber whereas only 12 isolates from the inner chamber of the Dandak cave were identified. Percent frequency of Aspergillus niger shown the highest frequency i.e, $66.67 \%$ with $9.57 \%$ as total percent contribution. Penicillium citrinum and Rhizopus stolonifer were the second most dominated species, isolated from the soil sediments collected from both the habitats and their percent frequencies were $50 \%$ whereas the percent contribution was $3.19 \%$ and $9.57 \%$ respectively.

The dominant microfungi families isolated from the mud sediments of both the chambers of the Dandak cave around the three seasons have been presented in Fig.-1. Interestingly from the outer chamber, the members of either Trichomacea (Rain and Winter) or Aspergillaceae (summer) were found to be dominated, whereas seasonwise no fixed pattern was found for inner chamber.

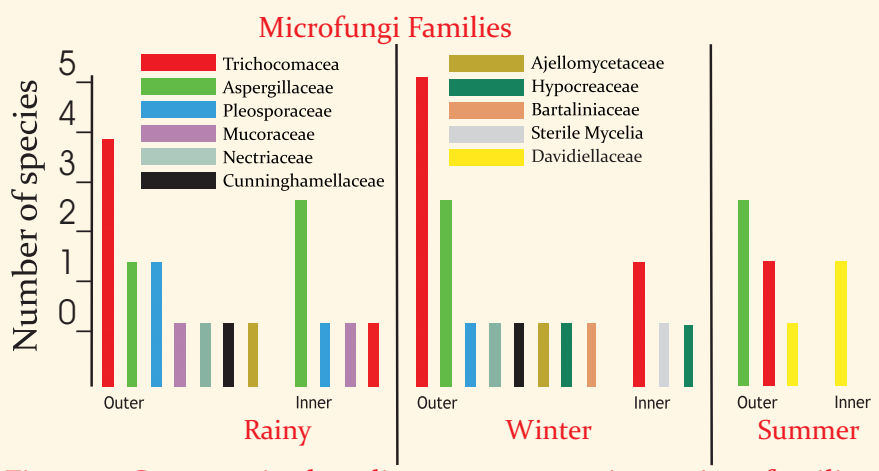

Figure-1: Comparative bar-diagram representing various families of microfungi the members of which have been isolated from floor sediments (mud) collected from both the chambers during three different season of a year.

During the winter season when we achieved maximum numbers of isolates. For comparison, we had also isolated the microfungi from the soil sediment collected from outside the cave. A comparative chart of the results belonged to three distinct habitats; inner, outer chambers of Dandak cave and outside the Dandak cave has
Ambient Science, 2019: Vol. 06(1); 26-30 DOI:10.21276/ambi.2019.06.1.ra04

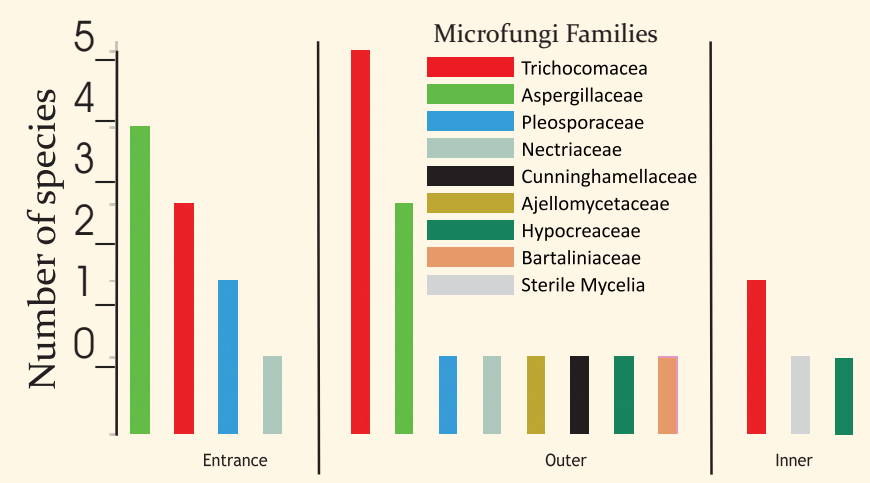

Figure-2: Comparative bar-diagram representing various families of microfungi, the members of which have been isolated from floor sediments (mud) collected from both the chambers and outside the cave during Winter.

been presented of in Table-2. The lowest numbers of fungi and their respective number of colonies was detected from the inner chamber of the Dandak cave whereas the equal numbers of microfungi species were evident from the outer chamber of the cave and from its epigean (outside) environmental zone, though the total numbers of colonies were isolated more from soil sample collected from outside the cave.

\section{Discussion:}

Due to the crises of intrinsic energy sources, the caves are always defined as the starved ecosystem (Vandel, 1965; Gunn, 2004; Biswas, 2009, 2010; Biswas \& Biswas, 2017). Thus, the microorganisms which grow on such energy starved conditions are often referred to as extremophiles. The possibilities for obtaining potent enzymes, useful as biotechnological tools are always more from such microorganisms which grow in extremophile conditions. In the present piece of work, we have compared mainly the patterns of microfungi occurrence from two distinct chambers of Dandak cave which differs from each other in various microclimatic conditions (Biswas \& Shrotriya, 2011; Biswas et al., 2017). Our result evidenced the growth of very selective types of microfungi in the inner chamber whereas the fungal diversity for the outer chamber was found to be sound. During Summer we found two members of Cladosporium from the inner chamber which was not evident from the outer chamber against any other season. Cladosporium spores are able to disperse even in a small air current and the species may grow on any such surfaces where moisture is high (Kwon et al., 20o1; Ogórek et al., 2012). Possibly, this is the reason of its survival inside the inner chamber. Earlier also species of Cladosporium was reported from the cave soil (Bensch et al., 2010). Once the occurrence of Trichoderma sp. from the inner chamber is also interesting, though the species was reported earlier also from the subterranean caves (Karkun et al., 2012; Nováková, 2009) and its importance for the cave could not be denied (Zhang et al., 2015). Possibly, the geophysical factors of the inner chamber during summer are favouring 
Table-1: Seasons dependent microfungi isolated from the floor sediments (mud) collected from 2 different habitats of Dandak cave

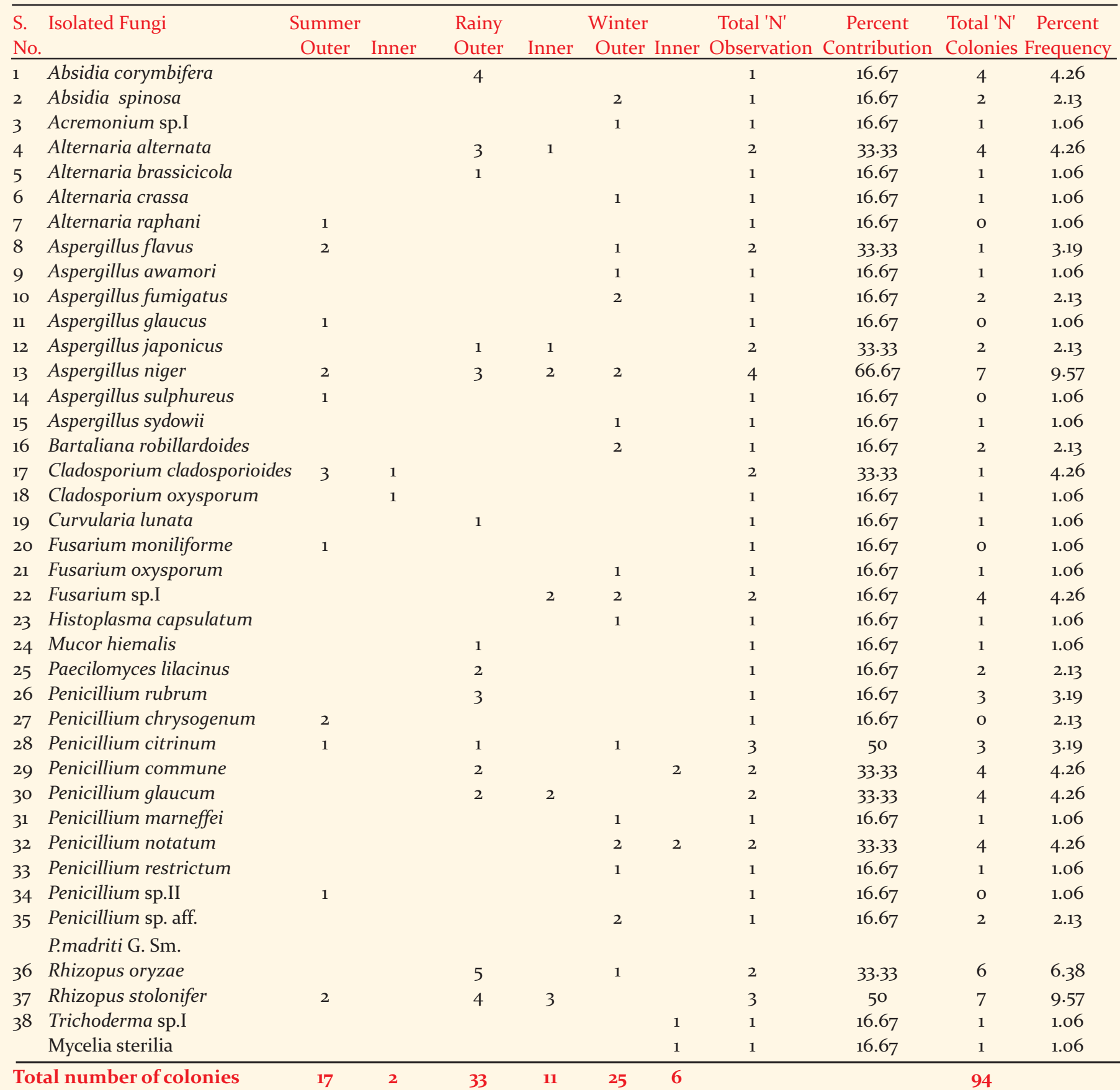

its proliferation (Biswas \& Shrotriya, 2011).

Though the outer chamber has the direct contact with the outer epigean environment, the transportation of external spores from the air, animals' visitation and even water stream entering from there overall increases the chances of growing more varieties of microfungi in the outer chamber. The most common fungal species group; Aspergillus and Penicillium are ubiquitous in worldwide caves. It is well known that Aspergillus species are highly aerobic in nature and grows only in oxygen-rich environments (Bolu et al., 2014; Chehri, 2013). Varieties of Aspergillus sps. isolated from the samples collected from the outer chamber. The chamber is highly influenced by the epigean environmental factors is directly support the same fact. Aspergillus niger which was most abundantly found could grow safely in all such environment which is devoid of key nutrients. The species has been well documented from the various caves all over the world (Cunningham et al., 1995; Nováková, 2009; Martin-Sanchez et al., 2014; Taylor et al., 2014; Zhang et al., 2017). But the member of the species was not evident from the inner chamber except for the Rainy season. Perhaps the microclimatic conditions inside the inner chamber do not support its proliferation.

The most interesting finding in this issue was the 
RESEARCH ARTICLE

Table-2:Three habitats dependent micro-fungi isolated from the floor Sediments (mud) collected during Winter season

\begin{tabular}{|c|c|c|c|c|}
\hline $\begin{array}{l}\text { S. Isolated Fungi } \\
\text { No. }\end{array}$ & $\begin{array}{l}\text { Outside } \\
\text { Cave }\end{array}$ & $\begin{array}{l}\text { Outer. Inner } \\
\text { cham. cham. }\end{array}$ & $\begin{array}{l}\text { Percent } \\
\text { Contri. }\end{array}$ & $\begin{array}{l}\text { Percent } \\
\text { Freq. }\end{array}$ \\
\hline 1. Absidia spinosa & 2 & 2 & 66.67 & 6.349 \\
\hline 2. Absidia corymbifera & 1 & & 33.33 & 1.587 \\
\hline 3. Acremonium sp.I & & 1 & $33 \cdot 33$ & 1.587 \\
\hline 4. Alternaria alternata & 1 & & 33.33 & 1.587 \\
\hline 5. Alternaria crassa & & 1 & 33.33 & 1.587 \\
\hline 6. Aspergillus albus & 1 & & $33 \cdot 33$ & 1.587 \\
\hline 7. Aspergillus awamori & 2 & 1 & 66.67 & $4 \cdot 762$ \\
\hline 8. Aspergillus flavus & 2 & 1 & 66.67 & $4 \cdot 762$ \\
\hline 9. Aspergillus fumigatus & 2 & 2 & 66.67 & 6.349 \\
\hline 10.Aspergillus niger & 5 & 2 & 66.67 & 11.11 \\
\hline 11. Aspergillus sydowii & & 1 & $33 \cdot 33$ & 1.587 \\
\hline $\begin{array}{l}\text { 12. Bartaliana } \\
\text { robillardoides Tassi }\end{array}$ & & 2 & 33.33 & 3.175 \\
\hline 13. Curvularia lunata & 1 & & 33.33 & 1.587 \\
\hline 14. Fusarium moniliforme & 2 & & $33 \cdot 33$ & 3.175 \\
\hline 15. Fusarium oxysporum & & 1 & $33 \cdot 33$ & 1.587 \\
\hline 16. Fusarium sp.I & 1 & 2 & 66.67 & $4 \cdot 762$ \\
\hline $\begin{array}{l}\text { 17. Histoplasma } \\
\text { capsulatum }\end{array}$ & & 1 & 33.33 & 1.587 \\
\hline 18.Mucor sp.I & 2 & & $33 \cdot 33$ & 3.175 \\
\hline 19.Paecilomyces lilacinus & 2 & & 33.33 & 3.175 \\
\hline $\begin{array}{l}\text { 20.Penicillium } \\
\text { chrysogenum }\end{array}$ & 1 & & 33.33 & 1.587 \\
\hline 21. Penicillium citrinum & 2 & 1 & 66.67 & 4.762 \\
\hline 22.Penicillium commune & 1 & 2 & 66.67 & 4.762 \\
\hline 23.Penicillium digitatum & 1 & & $33 \cdot 33$ & 1.587 \\
\hline 24.Penicillium marneffei & & 1 & $33 \cdot 33$ & 1.587 \\
\hline 25.Penicillium notatum & & 2 & 66.67 & 6.349 \\
\hline 26.Penicillium restrictum & & 1 & $33 \cdot 33$ & 1.587 \\
\hline $\begin{array}{l}\text { 27.Penicillium sp. aff. } \\
\text { P.madriti G. Sm. }\end{array}$ & 2 & 2 & 66.67 & 6.349 \\
\hline 28.Penicillium sp. & 1 & & $33 \cdot 33$ & 1.587 \\
\hline 29.Rhizopus oryzae & & 1 & $33 \cdot 33$ & 1.587 \\
\hline 30.Trichoderma sp. & & 1 & $33 \cdot 33$ & 1.587 \\
\hline Mycelia sterilia & & 1 & $33 \cdot 33$ & 1.587 \\
\hline
\end{tabular}

occurrences of some unique microfungi from soil sediments of the outer chamber which were neither isolated from the soil of its epigean counterpart nor from the inner chamber. During Winter, Bartaliana robillardoides Tassi, had been isolated from the outer chamber of the cave which is a very rare and biotechnologically sound microfungus. Earlier it was reported from the leaves of a medicinal plant Aegle marmelos Correa ex Roxb., and it is used as an anticancer drug produced by endophytic fungus (Gangadevi \& Muthumary, 2008). During Rain Paecilomyces lilacinus (Thom) Samson was also found from the soil sediment of the outer chamber. It is a soil fungus widely used for biological control i.e., efficient as nematicide (Kerry, 1990; Schenck, 2004) and also to check the of greenhouse insects and mite pests (Fiedler \& Sosnowska, 2007).
Ambient Science, 2019: Vol. 06(1); 26-30 DOI:10.21276/ambi.2019.06.1.ra04

For any ecological niche, the chances for occurrences of more microfungi are always more during Rainy season, as the high humidity, moist media, and other various biotic, as well as abiotic factors, support the same. Nevertheless, our study evidenced the abundance of isolates from the outer chamber of Dandak cave during the Winter season. During Rain, frequent water flushing possibly not allowing the proliferation of microfungi properly in the floor sediments of the outer chamber of the cave. It is to be added here that the location where Dandak cave is situated is a deep jungle, surrounded by big trees. The place is always blessed by winter rain (Biswas, $1992 \mathrm{a}, \mathrm{b}$ ). Somehow, little winter rain is always promoting the growth of microfungi and its proliferation in the same region.

For further comparison, during the Winter season, we have also collected the mud sample from the epigean (outside the cave area) envirtonmental condition and isolated the microfungi. It was very interesting see that the members of the Aspergillaceae family (both numbers of colonies and varieties) were found to be maximum from the sample collected from outside the cave area which gradually diminished from the sample collected from the outer chamber of the Dandak cave and finally no member was found from the sample collected from the soil sample collected from the inner chamber.

The species dynamics for the outside open area of the cave and the outer chamber is comparable during the winter season in addition to it some notable species of microfungi were also isolated from the floor sediments (mud) of the outer chamber of the Dandak cave which altogether indicate that the outer chamber of the Dandak cave which enjoys the privileges of ep[igean environmental condition, as well as partial sterile condition of cave ecosystem, is more potent for producing rare microfungi which could be useful forvarious biotechnological tools.

Acknowledgements:

Thiswork has been partially supported by Chhattisgarh Council of Science and Technology, Raipur Chhattisgarh under the MRP Scheme (1942/CCOST/MRP/14). We are thankful to the Forest Dept. of Chhattisgarh for providing permission to work in the National Park. Thanks are also due for Mr. Siddharth Biswas \& Mr.

Jitendra Nakka of Nat. Cave Res. Prot. Org. for their unreserved coopertionin the field. Special thanks to Dr. Devyani Sharma her her coperation during laboratory work.

\section{References:}

Barnett, H.L. \& Hunter, B.B. (1998): Illustrated Genera of Imperfect Fungi. Pub. by: Amer Phytopathological Society; Illustrated edition.

Bastian, F., Jurado, V., Novakova, A., Alabouvette, C. \& SaizJimenez, C. (2010): The microbiology of the Lascaux Cave. Microbiology, 156(Pt3):644-652.

Bensch, K., Groenewald, J.Z., Dijksterhuis, J., Starink-Willems, M., Andersen, B., Summerell, B.A., Shin, H.D., Dugan, F.M., Schroers, H-J., Braun, U. \& Crous, P.W. (2010), Species and ecological diversity within the Cladosporium cladosporioides 
complex (Davidiellaceae, Capnodiales). Stud. Mycol.,67:194.

Biswas, J. (1992a): Influence of epigean environmental stress on a subterranean cave ecosystem: Kotumsar. Biome ,5(1):39-43.

Biswas, J. (1992b): Kotumsar Cave ecosystem: an interaction between geophysical, chemical and biological characteristics. NSS Bull., 54:7-10

Biswas, D. \& Biswas, J. (2017): Major Deteriorative, Pathogenic and Benef icial Fungi Reported from various subterranean caves of the world: a mini review. Int. J. Ecosys., 7(1):11-16.

Biswas, D., Sharma, D. \& Biswas, J (2017): Habitat and season dependent the invasion of micro-fungi in decaying wooden flinders: a case study of the Dandak cave of Chhattisgarh, India. Ambient Sci., 04(2):22-26.

Biswas, J. (2009): The biodiversity of Krem Mawkhyrdop of Meghalaya, India, on the verge of extinction. Current Sci., 96(7):904-910.

Biswas, J. (2010): Kotumsar cave biodiversity: a review of cavernicoles and their troglobiotic traits. Biodivers. Conserv.,19(1):275-289.

Biswas, J. \& Shrotriya, S. (2011), Dandak: a mammalian dominated cave ecosystem of India. Subterranean Biol., 8:1-7.

Boddy, L.J.T. (2008): Interactions between Basidiomycota and invertebrates, pp. 153-177. In: Boddy, L., Frankland, J.C., van West, P. (eds.) Ecology of Saprotrophic Basidiomycetes. Pub. by:Academic Press, London.

Bolu, S.A., Elelu, N., Ahmed, R.N., Solaojo, F.E., Daramola, K.F., Omotosho, V.S. Atitebi, A.G. \& Afeni, M. (2014): Effect of vitamins, amino acids and phyto-active biomolecules on in poultry production, pp. 23-45. In: Pharmacology and Therapeutics.Vol.- II . Pub. By: IntechOpen.

Chehri, J. (2013): Factors affecting the growth of biomass of Aspergillus niger. Med. Pub. Health, 1(1):1-5.

Cunningham, K.I., Northup, D.E., Pollastro, R.M., Wright W.G. \& LaRock, E.J. (1995): Bacteria, fungi and bioKarst in Lechuguilla Cave, Carlsbad Caverns National Park, New Mexico. Environ. Geol., 25(1):2-8.

Cwalina, B. (2008): Biodeterioration of concrete. Arch. Civil Eng. Environ. 4:133-140.

Fiedler, Z. \& Sosnowska, D. (2007): Nematophagous fungus Paecilomyces lilacinus (Thom) Samson is also a biological agent for control of greenhouse insects and mite pests. BioControl, 52(4:547-558.

Gangadevi, V. \& Muthumary, J. (2008): Taxol, an anticancer drug produced by endophytic fungus Bartaliana robillardoides Tassi, isolated from the medicinal plant Aegle marmelos Correa ex Roxb. World J. Microbiol. Biotech., 24(5):712-724.

Gilman, J.C. (1957): A manual of soil fungi, II Indian edition, Pub. by: The Iowa State Univ. Press. Ames, Iowa. P. 450.

Gu, Ji-D. (2003). Microbiological deterioration and degradation of synthetic polymeric materials: recent research advances. Int. Biodeter. Biodegr., 52(2):69-91.
Gunn, J. (2004): Encyclopedia of Caves and Karst Science. Pub. by: Fitzroy Dearborn, New York. P. 960.

Karkun, A., Tiwari, K.L. \& Jadav, S.K. (2012): Fungal Diversity of Mandeepkhol Cave in Chhattisgarh, India. Adv. Biores. 3(2):119-123.

Kwon, J.H., Kang, S.W., Kim, J.S. \& Park, C.S. (2001): Scab of Tea (Thea sinensis) caused by Cladosporium herbarum in Korea. Plant Pathol. I., 17(6):350-353.

Li, X.S., Arai, H., Shimoda, I., Kuraishi, H. \& Katayama, Y. (2008): Enumeration of sulfur-oxidizing microorganisms on deteriorating stone of the angkor monuments, Cambodia. Microbes Environ., 23(4):293-298.

Martin-Sanchez, P.M., Jurado, V., Porca, E., Bastian, F., Lacanette, D., Alabouvette, C. \& Saiz-Jimenez, C. (2014): Airborne microorganisms in Lascaux Cave (France). Int. J. Speleol., 43(3):295-303.

Nováková, A. (2009): Microscopic fungi isolated from the Domica Cave system (Slovak Karst National Park, Slovakia). A review. Int. J. Speleol., 38(1):71-82.

Ogórek, R. (2017): Fungal communities on rock surfaces in Demänovská Ice Cave and Demänovská Cave of Liberty (Slovakia), Geomicrobiol.J., 35(4):266-276.

Ogórek, R., Lejman, A., Pusz, W., Miluch, A. \& Miodynska, P. (2012): Characteristics and taxonomy of Cladosporium fungi. Mikologia Lekarska, 19(2):80-85.

Poulson, T.L. \& Lavoie, K.H. (200o): The trophic basis of subsurface ecosystems, in: Wilkens, H., Culver, D.C., Humphreys, W.F. (eds.) Subterranean Ecosystems. Pub. by:Amsterdam; Elsevier, New York. P. 791.

Sterflinger K. (200o): Fungi as geologic agents. Geomicrobiol. J., $17(2): 97-124$.

Stokland, J., Siitonen, J. \& Jonsson, B.G. (2012): Biodiversity in Dead Wood. Pub. by: Cambridge University Press, Cambridge. P. 509.

Taylor, E.L.S., Ferreira, R.L., Cardoso, P.G. \& ResendeStoianoff, M.A. (2014): Cave entrance dependent spore dispersion of filamentous fungi isolated from various sediments of an iron ore cave in Brazil: a colloquy on human threats while caving. AmbientSci., 1(1):16-28

Vandel, A. (1965): Biospeleology: The Biology of Cavernicolous Animals (1st Ed.). Pub. by: Pergamon Press, Oxford. P. 552

Vanderwolf, K.J., Malloch, D., McAlpine, D.F. \& Forbes, G.J. (2013): A world review of fungi, yeasts, and slime molds in caves. Int. J. Speleol., 42(1):77-96.

Zhang, T., Chaturvedi, V., Chaturvedi, S. (2015): Novel Trichoderma polysporum Strain for the Biocontrol of Pseudogymnoascus destructans, the Fungal Etiologic Agent of Bat White Nose Syndrome. PLoSONE, 10(10): eo141316. 